\title{
Importance of intellectual property in technologic transfer
}

\author{
Dan Săvescu ${ }^{1}$ \\ ${ }^{1}$ Product Design, Mechatronics and Environment Department, Transilvania University of \\ Braşov, Romania \\ E-mail: dsavescu@unitbv.ro
}

\begin{abstract}
Paper presents some aspects regarding the protection of innovative ideas. All the research results of people involved in this activity must be protected by law against counterfeiting and piracy. It should be borne in mind that there are issues of novelty and license papers / dissertation of students, not only at the level of doctoral training. So university policies on intellectual property knowledge should include acquiring of knowledge ever since the II-III study year.
\end{abstract}

Keywords: intellectual property, technologic transfer, university policy, law, copyright

\section{Introduction}

Each scientific research has an element of novelty. It is necessary to awareness the importance of Intellectual Property protection of all novel parts of research, doesn't matter the level of researcher: student, license diploma, dissertation diploma, Ph.D., teachers, researchers, a.s.o. The policy doe in Universities must (sometimes is recommended) include courses of Intellectual Property presented by an engineer specialist, because the objects of Intellectual Property are produced by industry, are included technical aspects, appreciated only by a technician person. A lawyer is responsible for the Rights, what lies to inventor researcher applying research results, but protected by national law. Such protection is important against counterfeiting and copying, obtaining undue benefits by another person other than the inventor.

\section{Connection between innovation and intellectual property (IP)}

Innovation is the creative process (generating ideas) followed by making the changes generated by it. Products or system innovation must be protected. The State Office for Inventions and Trademarks OSIM, is the structure involved in IP protection, as central public administration, subordinated to the Government, establish the development strategy of industrial property protection in Romania and also implements the Government policy. The legal basis which entitles these above mentioned attributes is the Government Decree no 573/1998. IP has long been recognized and used by the industrialized countries and is being used by an ever increasing number of developing countries as an important tool of technological and economic development [1].

Many developing countries are aware that IP is their biggest interest, first of all, to establish the national IP systems where they do not exist and, after, to strengthen and upgrade the existing systems which, inherited from their historical past, are no longer adequately responding to new needs and priorities. Countries have laws to protect industrial property for two main reasons, related to each other. The first one is to give statutory expression to the moral and economic rights of creators in their creations, and the other is to promote, as a deliberate act of government policy, creativity, 
dissemination and application of its result and, at the same time, to encourage fair trading, thus contributing to economic and social development. The materialization of IP protection is represented by industrial property rights, IPR, which allow the creator or owner of a patent or a brand to benefit from his work or investment. The industrial property rights are outlined in Article 27 of the Universal Declaration of Human Rights, which states that everyone should enjoy the protection of moral and material interests resulted from any scientific, literary or artistic production of which is the author. IP protection is regulated by the following laws: Law no 64/1991 on patents, GO no 41/1998 on property taxes in industry and their use approved by Law no 383/2002.

An efficient patent system contributes to the stimulation of innovation in three main ways.

First, the existence of the patent system, with the possibility of obtaining the exclusive right for an invention to work for a limited period of time, constitutes an important incentive for the inventive and innovative activity.

Secondly, the limited period of time during which the patent owner is entitled to prevent others from using his invention creates an environment which facilitates the efficient development and utilization of patented inventions. It protects the inventor against uncontrolled competition from those who have not taken the initial financial risk. It thus creates conditions in which the risk capital can be safely advanced for the transformation of an invention into an innovation. The inventor will be at ease to further develop the invention into a final, commercially polished, product or process that could be marketed and produce a benefit.

Thirdly, the patent system provides the framework for the collection, classification and dissemination of the richest store of technological information existing worldwide today. In other words, it contributes to the dissemination of new knowledge since the right of the inventor to prevent others from using his invention for a limited period is not freely granted. Innovation is often influenced by the environment in which innovators work. The factors that generate a favorable overall environment for inventions and innovation are: the state of science and technology; the legal, fiscal and general financial systems; the scientific and entrepreneurial culture; the technological and manufacturing infrastructure; human resources and their level of knowledge and education [2].

The specific factors that influence innovation are represented by the relationships between universities, financial institutions, governmental offices and industry networks among others.

Furthermore, the administrative and financial regulations governing the creation of new companies play an important role. At the same time, the national innovation support structures and programs for services should be viewed as a unified whole, with the main objective of increasing the capacity of society to generate inventions and innovations, including technology transfer, both at national and international level [2].

Technology transfer is the introduction or acquisition in the economic circuit of the technology and specific machines, equipment and facilities resulted from research, in view of new or improved processes, products or services, required by the market that induces an innovative behavior, including the disseminate information, to explain, to transfer knowledge, to provide consulting and communicate with people. This is carried out by the network of innovation and technology transfer entities (ARoTT or ReNITT). The infrastructure of Innovation and Technology Transfer was created and is functionally assessed and accredited by the National Authority for Scientific Research (ANCS) under GD no 406 12003 and aims to support economic and social development, foster innovation and technology transfer, attract investment to capitalize results of research and innovation, as well as human resources from the national research and development system. Its role is to support SMEs and the interface between them, as beneficiaries and producers of innovation, "inventors" (natural or legal persons) represented by universities, research institutes and companies with research and development activity. Innovation and invention support structures and services have to develop their own type of management, with planning and policies depending on the circumstances prevailing in each country.

Competitiveness is a complex concept which, at a general level, expresses the ability of persons, companies, economies, regions to maintain competition on the internal and / or especially international scale, and to get, in terms of a specific business environment, economic benefits, resulted in constant 
Thoth Publishing House

increases of productivity and standard of living. As a result, one can speak about SMEs' profitability. Research has shown that SMEs can and should contribute considerably to employment creation and trade, which ultimately promote economic growth. It has also been shown that, given the opportunity, SMEs are innovative and competitive. However, SMEs need to be encouraged to take full advantage of the existing intellectual property protection system in order to compete more successfully in the global economy. This is a snapshot of economic activity, both at micro, and macro levels, and the extent to which companies are in the competition and are competitive. Functioning as a binding element and a balance between the potential, resources and costs, research-development networks support SMEs in their efforts [6].
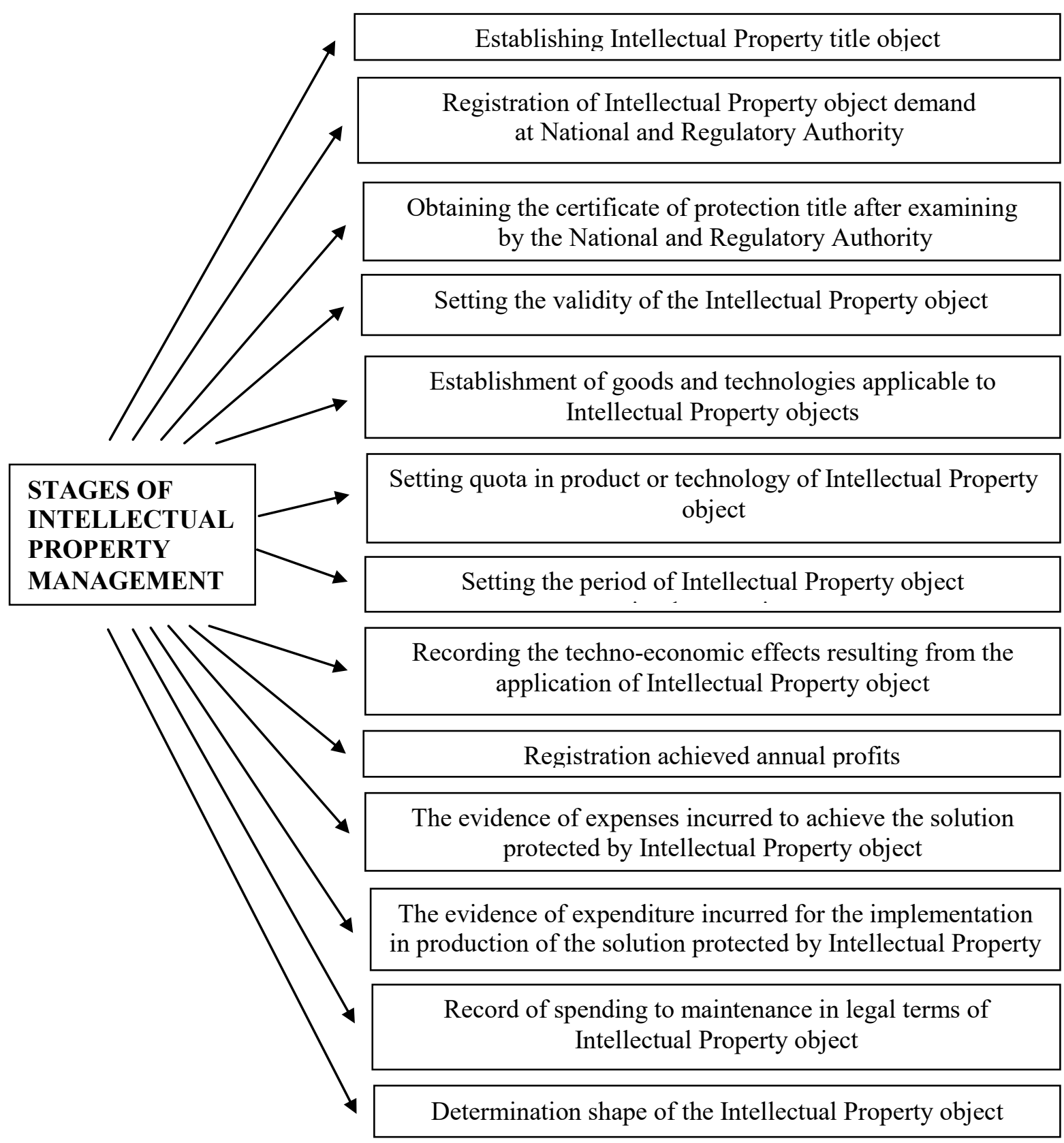

Figure 1. Stages of Intellectual Property management 


\section{Stages of intellectual property management in technologic transfer}

Main stages of the Intellectual Property management can be highlighted in 'Figure 1'.

Only stages number 3 and 4 are as responsible the National Authority (OSIM); in all the others is involved only the demander.

\section{Stimulation and awareness IP methodologies in universities}

Although different by their nature of activity, universities should not be seen as a self- centered system, but always take into account the labor market as a reference system compulsory to establish those landmarks necessary for self-definition in society. It should focus on the society's dynamic, graduates' development, the condition of secondary schools. Basically, the role of the university in society is to create culture. Moreover, for a contemporary approach, its role is also to provide welfare.

IP culture is an organizational value system resulting from an environment oriented to observing and protecting industrial / intellectual property. It consists of all the behavioral and professional reactions related to observing the right to intellectual property, reactions supported both by a law system and by a system of unwritten rules, structured over the time in institutions and society.

As a result to a study performed in the most important universities, the academic environment does not consider IP culture very substantial in the Romanian universities. Some reactions are very rough and they can sometimes be conditioned by an exaggerated self-critical attitude of those interviewed. Anyway, the general conclusion is that, at this point, one cannot talk about authentic quality culture in the Romanian universities[6].

The main coordinates of a university policy in the field should envisage the following operational systems:

- A system for assuring industrial property culture (education, good practice, operative information);

- An assessment system (procedures, methods, specialists);

- A capitalization system (regulations, service patents);

- An evaluation system (cessions, licenses, know-how).

There are some questions to realize main objectives such as:

a) setting up a network between the State Office for Inventions and Trademarks (OSIM), National Council for Scientific Research in Higher Education (CNCSIS) and Romanian universities, in order to allow and facilitate an inter-institutional information exchange and a practical framework able to stimulate research, ways of IP protection (using IP specific elements) and thorough use of research results;

b) setting up Technology Transfer Offices attached to certain universities; the TTOs will receive logistic support from OSIM.

c) extending the teaching of an IP course module (optional) in technical and economic universities in Romania. OSIM will grant assistance for this action.

d) ensuring access to European and international programs in the field of industrial property protection the rights for original creations made in universities;

e) jointly organizing seminars, symposia and round tables on current and resonant topics concerning industrial property protection in technical fields.

f) including in the Draft Law on employees' inventions (which was elaborated as a legislative initiative of OSIM in 2014 - 83 Law/2014) a special chapter concerning inventions made in the academic environment;

g) setting up, within CNCSIS, an office of about 3 persons, that should coordinate, at national level, the patenting activity within universities;

h) improving the current regulations with the purpose of increasing the importance of patents in awarding scientific degrees to university research staff and professors that are applicants and/or owners of those patents;

i) providing, within the framework of the programs coordinated by CNCSIS, specific funds meant to support the patenting with OSIM, or, in case of special valuable inventions, for getting European patents with the European Patent Office or international patents. 
Thoth Publishing House

The challenge for Romania is that universities and R \& D units to act as key generators of IP assets.

Factors involved in this activity:

- Teachers and researchers;

- Doctoral students, students in their final years, students generally;

- Sponsors;

- Units of technology transfer (TT);

- Intellectual property offices, regional offices / area;

- National Council of Small and Medium Enterprises (CNIMMC) and businesses;

- Chambers of Commerce and Industry etc.

Since there are sometimes contradictory interests, not very convergent, IP strategy should harmonize the interests of these factors included in universities and research institutes.

IP strategy based on the interests of stakeholders assumes hereinabove:

- Creating favourable conditions for the dissemination of new knowledge for the benefit of the public.

- Ensuring the fair and equitable sharing of financial and other benefits of innovative product marketing, recognizing the contribution of inventors, and the institution (university, R\&D unit).

- Promote, encourage and support scientific research.

- Attracting students to IP and capture young people's creativity.

- Creating incentives for researchers and providing rewards for intellectual capital.

IP strategy embraced by the team members must find answers to questions like:

1. Who holds the IP rights arising from research in government funding?

2. How will be distributed benefits of IP commercialization between researchers / inventors, department, institution, lender, etc.)?

3. There are legal provisions for IP commercialization of research results on government funding?

4. Who holds the IP rights of private funds for research?

5. To transfer technology (T.T.) to private sector companies for marketing using "spin - off" or license agreements?

6. Who manages IP assets, including negotiation of licenses and allocation of royalties?

7. To what extent institution encourages the commercialization of research results through entrepreneurial activity?

8. What funding is assured the payment of costs for obtaining and maintaining in force the PI?

9. How does the disclosure of an invention by a researcher?

10. How are treated conflicts of interest between the duties teaching or research and commercial projects?

It requires the organization of an administrative structure (office, department, etc.) or at least the appointment of a specialist to deal with the problems of protection of industrial property, an industrial property attorney attested by OSIM. The structure, reports directly to stuff (rector / senate, director technical, scientific, scientific-technical council etc.), it is good to include a lawyer (for contracts, disputes, lawsuits, etc.) and a secondary education specialist for keeping records for the various phases of implementation of inventions.

To achieve its purpose, the creation of the following operating systems:

- A system for providing industrial property culture (education, best practices, operational information);

- An evaluation system (procedures, methods, specialists);

- A system of capitalization (rules, patent department, department of IP);

- An evaluation system (assignments, licenses, know-how).

As activities should be followed:

- systematization of information about the state of the IP culture in Romanian universities;

- successful establishment of Romanian practices in the field (universities, research institutes, technologic transfer centres etc.);

- study level of development of IP culture in various universities in Europe;

- establishing successful European practices in the field; 
Thoth Publishing House

- dissemination of useful information, best practices in universities in Romania, research institutes;

- drawing reference material regarding national practices, successful methodologies promoted the country and its actualization at intervals, according to the new requirements, legislation, national and international political orientation etc.

Therefore, IP culture developed in universities can be expressed by identifying and assess the following indicators:

- tackles subjects that PI (implicit and explicit);

- number of teachers specialized in IP;

- number of students trained annually in IP;

- number of teaching guidance developed in the field;

- number of postgraduate courses etc.

Efforts in recent years in universities on promoting IP themes materialized by introducing training courses in this field at the doctoral (PhD School), possibly in the training programs of master in most cases these courses are held by lawyers .

From the personal point of view and embraced by other colleagues in the country (Iasi, Cluj Napoca, Timisoara, Bucharest etc.) these courses should be provided to the license level and having as teachers engineers (industrial property objects are engineering creations). This activity allows the development of creativity and entrepreneurship, business management through innovation since the early study years (semesters V, VI, VII).

\section{Conclusions}

The importance to promote IP knowledge in universities, especially in mechanical specialities is very well known, but not applied. Why? It is difficult to pose this question this years, when Romania is captured by Multinational Companies, where production is done. Projects are coming from outside, products are also from outside, market from them is already assured. Who need innovation in Romania? Only Romanian SMS. To resist on market with innovative Romanian products is something "crazy". It is a challenge for each Romanian company to stay on market. In this way protection of Innovative products by law is compulsory, exception Chinese market, where protection of intellectual property is "zero".

Something good: for students is good for them to know about the property rights coming from licence and dissertations theses. It appears Law 83/2014, law for service invention.

\section{References}

[1] Rothwell R 1994 Towards the Fifth-generation Innovation Process. International Marketing Review, vol.11, No.1, pp.7-31.

[2] Le Corre A, Mischke G 2006 The Innovation Game. A New Approach to Innovation Management and R\&D, Springer US

[3] Galanakis K 2011 Innovation process. Make sense using systems thinking. Technovation, november, pp.1222-1232

[4] Gann D, Dodgson M 2007 Innovation Technology: How New Technologies Are Changing The Way We Innovate, National Endowment for Science, Technology and the Arts, London, UK

[5] Kusiak A 2012 Innovation science: a primer. Int. J. Computer Application in Technology, Vol.28, pp.148

[6] Săvescu D 2010 Some aspects regarding the concept „Research and Business”. Journal of Industrial Engineering and Management, JIEM, Vol. 3 nr.2, pp. 337-352. 